\title{
TRADITIONAL VALUES, SOCIO-CULTURAL FACTORS AND HUMAN RESOURCE MANAGEMENT PRACTICES IN PUBLIC SECTOR ORGANISATIONS IN GHANA
}

\author{
K.O. Akuoko \\ Department of Sociology and Social Work \\ Kwame Nkrumah University of Science and Technology \\ Kumasi, Ghana
}

\begin{abstract}
The paper assesses the effects of traditional values (collective conceptions of what is considered good, desirable and proper or bad, undesirable and improper in a given society) and socio-cultural factors (these are models of life, human rights, value systems, customs, beliefs and arts) on human resource management (HRM) in public sector organizations in Ghana and the need for Human Resource (HR) Managers to "rethink their role, to overcome the difficulties inherent in their position”. Socio-cultural practices are the distinctive, spiritual, material, intellectual and emotional features that characterize a society or a social group. Ghanaian worker in general and the HR manager in particular is influenced by socio-cultural practices and values of a larger society of which he/she is a member. For instance, the HR manager is in dilemma as to whether or not to refuse a worker's permission to attend funerals, naming ceremonies, festivals or visit relatives at hospital during working hours. In other words, HR manager is at cross-roads as to what to do in order to maintain his/her job while holding on to his/her socio-cultural practices when some of these practices contravene the organizational code of conduct. Among these factors, is how to deal with the traditional values and socio-cultural environment within which (HR) specialists find themselves. The paper therefore focuses on the impact of some of the traditional values such as the pressure from family members, attitudes and socio-cultural factors. The purposive sampling technique was used to select the directors and the simple random sampling method was used to select the other respondents. Questionnaires were designed and self-administered questionnaire and face -to-face interview methods were used to obtain information for the study. Thus, the traditional values and socio-cultural factors, which the society maintains, remain strong among workers and have impacted on the work of HR specialist in spite of the conflicting values prescribed by the public sector organizations.
\end{abstract}

Keywords: Traditional values, socio-cultural factors, human resource management

58 Journal of Science and Technology, Vol. 28, No. 3, Dec., 2008 


\section{INTRODUCTION}

The conflict between bureaucratic processes and traditional values and socio-cultural practices poses a very big problem in the smooth management of human resource in organisations. Despite the perceived importance of human resource in public sector organisations, traditional values and socio-cultural factors pose difficulties. The welfare of human resource in organisations is of paramount importance and thus, "in so far as people are employed, the concern for people exists, however inarticulate it may be" (Lyons, 1971). The question then is to what extent is the HR manager expected to show concern for the people employed whilst keeping the organisational standards. Thus, HR Managers should "rethink their role, to overcome the difficulties inherent in their position" (Tyson et al., 1985). A look at the Ghanaian society today shows that, in spite of the rapid rate of modernization, Ghana still retains the norms of its sociocultural and traditional values. Modernization however comes with bureaucratic institutions and its inherent laid down procedures.

According to Armstrong (1992; 2001) Human Resource Management (HRM) is a strategic and coherent approach to the management of an organisation's most valued assets: the people working there who individually and collectively contribute to the achievement of its objectives. "Several factors have contributed to make public sector HRM a major problem area of management in Africa" (Akinnnusi, 1993). Nukunya (2003) and Assimeng (1999) indicate that the extended family system may be "any grouping broader than the nuclear family which is related by descent, marriage or adoption". Ollennu (1966) also states that the basic unit of Ghanaian society is the family, not the individual. The extended family system imposes a lot of responsibility on its members especially in the area of funeral attendance and contributions. Members are perceived as owing the family a responsibility to respond quickly to the call of the family head if any calamity befalls any family member. Thus, the individual is a product of the collective effort of all family members. "Funerals are re- garded as a duty and no pains must be spared to make them memorable" (Sarpong, 1974). Sarpong (1974) writes that the Ghanaian lays much store on the way in which funeral or the funeral of relatives is observed. Since the extended family system is broader the chances of losing a member is very high. And if Sarpong's idea of the importance of funerals to family members is something to go by, then each member will have a lot of funerals to attend in his/her life time. Peil (1972) in her study revealed that lateness among workers was rampant and many workers had never developed the sense of time necessary in urban industrial society. This was a clear indication of the effects of socio-cultural practices on worker behaviour. Blunt et al. (1990) and Nukunya (1992) hold that in Africa, favourable performance appraisal is linked more to particularistic criteria as against universalistic ones and "tribalism is motivated by a number of factors which in various combinations determine attitudes and behaviour towards members of one group or the other". Moser (1993) indicates that whereas the ideology of patriarchy has served to reinforce the popular stereotype of the male breadwinner, reality does not bear this out because low income women have important productive roles. It is also believed that "dwanetoa" the traditional concept of pleading for clemency has also been a bane of the HR specialist in public organisations.

Ghanaian workers, whose socio-cultural values, traditional norms and cultural practices influence their behaviour face a dilemma as to what to do in order to maintain their jobs whilst holding onto their socio-cultural values. Thus, this study was conducted to find out how HR specialists deal with the dichotomy in their role of effectively managing Ghanaian workers to achieve organizational goals without compromising organizational principles, and the importance of traditional values and the socio-cultural environment that they find themselves in.

The main objective of the study was to investigate the effect of traditional values and socio- 
cultural practices on the role of HRM in public sector organizations in Ghana.

\section{Hypotheses}

Ho: Inefficient HRM practice is a function of the extended family system.

$\mathrm{H}_{1}$ : Inefficient HRM practice is not a function of the extended family system.

Ho: "Dwanetoa" undermines the efficient performance of HR specialists.

H1: "Dwanetoa" does not undermine the efficient performance of HR specialists.

\section{METHODOLOGY}

Research design

The area of study was the Komfo Anokye Teaching Hospital (KATH) in Kumasi, the Ashanti regional capital in Ghana. The research started as an exploratory study since little was known about the problem. However, when more light was thrown on the problem the design became analytical.

\section{Sampling procedure}

The target population was all the directors, senior and junior staff in the organization. The study population of interest in the fieldwork was the directors and the other workers in the organization. The individual persons in the organization constituted the sampling units for the study. The survey population for the study was drawn from the list of workers obtained from the HRM directorate. The list constituted the sampling frame from which the study population was obtained. The total population for the study was 1,896 workers and out of this, 48 were directors. The simple random sampling technique was used to select 25 directors and 100 workers. Finally, the sample size of 125 respondents was selected for the study. The largeness of the sample size was to ensure adequate representation of the workers that were selected for the study.

\section{Data collection}

Data were collected from two main sources primary and secondary sources. The existing data from documentary sources including pub- lished literature, office files/records, personal records and the internet search for current publication and information were evaluated. The selfadministered questionnaire and face-to-face interviewing methods were used to collect primary data. The self-administered questionnaire method was used to elicit information relevant for the study from the directors and some of the workers because they were well educated and could read, understand and respond to the questions appropriately. The face-to-face interviewing method was used for some workers who could not complete the questionnaire themselves. It ensured that all questions were answered and all responses were received. It saved time, reduced call backs and questionnaire mortality rate.

\section{RESULTS AND DISCUSSION}

HRM in Ghana, as a vehicle of administration, is a colonial legacy from the British. This has been adopted by organisations found in the industrial societies and has been set up in Ghana to fulfil similar functional needs. A critical examination of traditional values and socio-cultural factors in the study also revealed that they have had some impact on the operations of the HR managers in organisations.

\section{The Impact of Traditional Values on HRM}

A look at the Ghanaian society reveals that although Ghana has undergone rapid changes as a result of the influence of Christianity, Islam and Colonialism, Ghana still retains most of its aged old traditional norms that have been passing from generation to generation (Sarpong, 1974). These traditional norms include strong passion for funerals, shared responsibility for extended family members, lateness inherent in the concept of time, the concept of "dwanetoa" and many others. This has had a serious debilitating effect on the role of HRM in public sector organisations. The focus of life is gradually shifting to the urban centres. However, the norms of the society are mainly enshrined in the traditional cosmological pattern. Traditional values that the

60 Journal of Science and Technology, Vol. 28, No. 3, Dec., 2008 
society maintains remain strong among workers in spite of the conflicting values such as fairness, value for time and hot stove concept in discipline prescribed by the public sector organisations.

\section{Attitudes}

Attitudes are learnt and enduring tendency to perceive or act towards persons or situations in a particular way. Therefore to the question "Do the demands of the extended family members conflict with organisation's rules and regulations, 63 (50 percent) responded in the affirmative and explained that the attitudes (such as expecting free medicare from relatives who work in the health service, favouritism) of the extended family members indicated a complete failure to recognise the existence of conflicting demands faced by relatives in bureaucratic organisations. The relatives in such a situation failed to understand that the HR specialist had organisational obligations that interfered with the wishes of the extended family. Added to this was the perception of the familial pressure which involved potential conflict between the role of HR specialists and family demands. Though majority of the respondents (78: 61.9 percent) indicated that visitors were seen on first -come first-serve basis, a significant number (26: 20.6 percent) explained that the family members expected bosses to see to their needs first before anybody else. It is evident in the Ghanaian social structure especially with the extended family system as the basic unit of the social network that relatives would exert pressure on the HR specialist and expect him to honour the obligations of the family. This is more pronounced in a situation where the members of the family contributed towards the education of the HR manager (Blunt et al., 1990); even though there are rules and regulations in the organisations the HR specialist has to adhere to. There is, thus, a close relationship between the expectations of relatives and the way HR managers behave.

The Ghanaian attitude to work has had a serious adverse effect on the operations of the public organisations and the role of HRM in general. Very often the enforcement of rules and regulations in order to instil discipline in the work organisation would be met with comments such as "this is government work, it is not your father's property" "you will leave and the work will continue .....". Under such circumstances, the HR manager becomes frustrated and may not be able to cope with the situation because he becomes unpopular among the workers. Ultimately, he has to retreat and perform in a way to satisfy the whims of the workers which would adversely affect output levels and may gradually fall out of business.

\section{Pressure from Family Members}

According to Blunt et al. (1990) the efforts of the family in contributing towards the education of relatives were considered as investment which must yield dividends. The HR specialist would thus be expected to provide employment for an unemployed kin. The refusal of an HR specialist to help an unemployed kin would be interpreted as having abandoned his family as a result of his upward social mobility. The members of the family through whose contribution the HR manager was made, would feel that they had been let down by somebody whose duty it was to help them. Thus, when the respondents were asked if the family members were too demanding, 33 (26.2 percent) responded in the affirmative, 25 (19.8 percent) answered negatively whilst 68 (54 percent) indicated that the family members sometimes put pressure on them. These responses indicate that family members of the HR specialist put pressure on him/her, thereby making it difficult for him/her to carry out the job as a competent HR specialist.

This situation was likely to occur based on the statement that in Ghana the family continued to be the important unit of personal identity (Price, 1975). It was only reasonable to argue that individuals would not like to be seen as inconsiderate towards their families, and would wish to avoid the impression that they do not have an interest in the family's well-being. It is there- 
fore, not surprising that the HR specialist may conform to the expectations of his kinship group. However, it is the belief that in the foreseeable future, education will make a remarkable impact on the influence of the extended family on the role of HR specialist. Presently most educated elites in Ghana are attached to the nuclear family system which emphasizes the need to look after the spouse and children. Furthermore, the difficulties of urban life coupled with limited incomes and resources may compel people to concentrate on their spouses and children rather than the extended family members (Nukunya, 2003).

The Impact of Socio-Cultural Factors on HRM: Some of the norms of the Ghanaian socio-cultural factors conflict with the role of HRM in organisations. The corporate nature of the Ghanaian society - the extended family and the importance attached to funerals, festivals place strains on the role of HRM in organisations.

\section{The Extended Family System}

The place of the extended family in the social organisation of Ghanaians was stressed by Ollennu (1966). He noted that "the basic unit of Ghanaian society is the family, not the individual. Almost everything affecting the individual is dealt with by his family. When the individual offends anyone his conduct is reported to the head of his family who, with his elders will go into the matter and take appropriate steps to make amends. If he/she achieves something good, his family gets the praise". He/she also has responsibilities towards family members. He/she is under obligation to share in the grim and support family members.

The HR manager, just like any other urban worker is not only committed to the obligations of the formal work environment but also to the extended family and other reference groups. There is as a result, lack of congruity between HRM and the traditional values and sociocultural factors in which it is embedded. The HR specialist is thus in a dilemma. He is being pulled on one hand by the strings of the sociocultural factors and those of his roles on the other. Consequently, the HR specialist is caught up between two worlds - obeying the norms of his socio-cultural environment as well as those of the organisations. The refusal therefore of an HR specialist to help an unemployed kin would be interpreted as having abandoned his family as a result of his upward social mobility. Hence, majority of the respondents (68: 54 percent) explicated that the demands of the extended family conflicted with the organisation's rules and regulations. However, 59 (46 percent) were of the view that it did not conflict with the organisational rules. In any case, they admitted that the extended family system had affected their performance in the organisation. There was considerable body of evidence in the strength of the extended family among civil and public servants. This portrayed a lack of self-reliance owing to the prevailing influence of the extended family system. Thus, it had not been easy for many people, including HR specialists, to solve problems by themselves, thereby making people always dependent on social support as has been illustrated by Ollennu (1966).

Generally in Ghana everybody is responsible for the other in such a way that if parents die, it becomes difficult to differentiate orphans from non -orphans because they are automatically fused into the family and taken good care of. Also, if parents are poor and unable to bring up or educate their children, that responsibility falls on those who are capable in the family such as uncles, grandmothers and other family members.

It is an accepted fact, however, that the extended family is in a transition. This is because industrialization has brought about urbanization, which has somehow shaken the very roots of the extended family. In the words of Assimeng (1999) one of the dilemmas facing people in transitional societies is that such people usually desire the best of both worlds. These desires are the economic and emotional security in the traditional order and the freedom from restraints, and the high standard of living which one acquires in

62 Journal of Science and Technology, Vol. 28, No. 3, Dec., 2008 
the modern industrial order.

It is obvious to some extent though, that the process of urbanization in particular and modernization now affects the extended family in general. But one should not forget that, socialization comes with its attended assimilation of norms, values and practices, and it is very difficult if not impossible to let go such important values of a group that one belongs to in spite of the influence of change. In fact, these values are usually very well entrenched in the belief systems that, going contrary to them, it is believed may have spiritual consequences which one would want to avoid anyway. This has resulted in the ambivalence of HR managers as to whether to follow the work ethics or sociocultural practices and traditional values.

It should also be emphasized that, the urban dweller and for that matter the HR manager, who might not have escaped from help from his extended family in his upbringing and or education owes an obligation to them in the form of some kind of reciprocity. That is to say he will be expected to somewhat pay back this help to subsequent generations in either the same form from which he benefited or by offering job opportunities once he is in the position to help. His family's expectations might be in contrast to his obligations as a public servant.

Thus, in assessing whether inefficient HRM practice is a function of the extended family system based on empirical work, about 14 percent of the entire variations of the explanatory variables regressed on the dependent variable i.e. the $\mathrm{R}^{2}$ explains the low influence of the extended family system on HRM practice while about 86 percent were unexplained. Hence, the null hypothesis could not be rejected in favour of the alternative hypothesis (i.e. H1: Table 1). This result confirms Nukunya's opinion that the difficulties of urban life coupled with limited incomes and resources may compel people to concentrate on their spouse and children rather than the extended family members. Thus, HR specialist is no exception to this assertion.

\section{Funerals}

The way funerals are celebrated gives credence to the importance attached to funerals in Ghanaian society. When the respondents were asked about the importance of funerals, 112 (88.9 percent) answered in the affirmative. They elucidated the fact that death marks the end of life and it is believed that if a dead person is not well prepared for his journey to the spiritual world, he would not be accepted and this would result

Table 1: F-statistics for whether or not inefficient HRM practice is a function of the extended family system

\begin{tabular}{cccccccccc}
\hline Model & R & R Square & $\begin{array}{c}\text { Adjusted R } \\
\text { Square }\end{array}$ & $\begin{array}{c}\text { Std. Error of } \\
\text { the Estimate }\end{array}$ & $\begin{array}{c}\text { Change } \\
\text { R Square } \\
\text { Change }\end{array}$ & F Change & $\begin{array}{c}\text { Statistics } \\
\text { df1 } \\
\text { df2 }\end{array}$ & $\begin{array}{c}\text { Sig. F } \\
\text { Change }\end{array}$ \\
\hline 1 & .373 & .139 & .081 & .63232 & .139 & 2.369 & 8 & 117 & .021 \\
\hline
\end{tabular}

a) Predictors: (Constant), Do your family members expect you to see to their needs first, before anybody else when they visit you at your work place? , Has the extended family system affected your work life in any way?, How has the extended family system affected your work?, Did you in anyway benefit from your extended family in the course of your education?, Do you think the extended family system is too demanding?, What has been your attitude/response to family members in times of need?, Do your family members exercise patience when they need help from you at your work place?, Do some of these demands conflict with your organization's rules and regulations?

b) Dependent Variable: In your opinion, do you think the practice of the extended family system should be encouraged? 
in a bad omen for the deceased person's community.

Funerals also portray the strong kinship bond in the Ghanaian society. The kinds of questions that are asked after funerals are, for example, "how was the attendance? Was it exciting?" (Sarpong, 1974). Funerals must be successful. Not infrequently, one hears comments on whether some particular relatives were present. It is therefore not surprising that a large number of Ghanaian workers consider it necessary to leave their jobs to attend funerals. The HR specialist is confronted with the difficult task of reprimanding workers who do not come to work because they had to attend funerals of deceased relatives without obtaining permission. Despite the fact that most collective bargaining agreements and the civil service code of conduct allow staff to attend funerals of deceased spouse, children and legitimate parents, strict compliance of this provision in the public sector context has not been successful. Workers sometimes take advantage of this provision to do otherwise. A personnel officer who initiates disciplinary measures against offenders may be considered deviant in the Ghanaian society since there is a popular saying that "death is a universal problem". It has become very necessary to support bereaved workers because apart from the generally low levels of salaries prevailing in the public service, funerals today have become so expensive that, without such a 'push' a lot of people find it difficult funding their funerals. As a motivational factor therefore, HR mangers have not much choice but to support their staff financially when they are bereaved. Armstrong (1991) states that bereavement is a time when many people need all the help and advice they can get. Almost all the respondents (116: 92.1 percent) indicated that the organisation makes provision to help bereaved staff members. In Ghana this gesture would go a long way to boost morale of workers in the work places because of the importance they attach to funerals.

To the question "Do you easily get permission to attend funerals, 38 (30.2 percent) respondents explained that they easily obtained permission to attend funerals. Apart from the financial support, an important issue is absenting oneself from work to attend funerals. Thus, the HR manager can be in a dilemma as to the granting of permission to staff to attend funerals if it did not conform to the tenets of the Collective Bargaining Agreement (CBA). Policies are supposed to regulate behaviour in an organisation; therefore the proper adherence to them is what is expected. But to prevent someone from attending an extended family member's funeral might be unheard of in the Ghanaian context. But 88 (69.8 percent) of those who were interviewed specified that they did not easily obtain permission to attend funerals. In fact, the HR manager who initiated disciplinary measures against staff who absented themselves from work to attend funerals may be branded a deviant.

\section{Lateness and Absenteeism}

Generally, it is observed that some workers in Ghana are sometimes late for work due to transportation problems; occasionally most people arrive late at the work place or absent themselves because they visited relatives in their home towns and failed to arrive back on time. When the workers were asked about what particular days they reported late for work or absented themselves from work, 20 (15.9 percent) mentioned Mondays and Fridays. They further expounded that these days are unique because on Fridays people normally use it to prepare for funerals and church service weddings. On Mondays, as a result of week-end activities, workers may be recovering from fatigue or preparing the home for the new week. As a result they are always late for work. It is also observed from the data that most female workers very often report late to work sometimes due to their responsibility as wives and mothers to complete household chores. In some cases, women employees absent themselves from work as a result of a child's illness without obtaining permission from the workplace. This was expressed by 68 percent of the respondents.

64 Journal of Science and Technology, Vol. 28, No. 3, Dec., 2008 
It may be noted that the study by Peil (1972) revealed that lateness among workers was rampant and many workers had never developed the sense of time necessary in urban industrial society. It is thus reasonable to argue that although lateness and absenteeism are mainly due to transportation problems as indicated by 25 (19.8 percent) respondents during the study, sight must not be lost of the fact that pressing family issues are also contributory factors. Thus, 26 (20.6 percent) respondents revealed that illhealth of family members, and sending children to school (23: 18.3 percent) were identified as some of the reasons for lateness and absenteeism.

\section{Discrimination}

Blunt et al. (1990) hold that in Africa, favourable performance appraisal is linked more to particularistic criteria as against universalistic ones. For example, an appraiser may have close ethnic or kinship relations, thereby resulting in unequal treatment whereby one set of standards, procedure or facilities are used for a particular group and another for others. According to $\mathrm{Nu}-$ kunya (1992), "tribalism is motivated by a number of factors which in various combinations determine attitudes and behaviour towards members of one group or the other".

Discrimination, a canker in the Ghanaian social structure has contributed negatively to the effectiveness of the role of HRM in public sector organisations. One of the findings of the study is that heads of most organisations ignore the criteria set forth for the appointment of candidates to vacant positions so that they can employ their tribesmen. Hence, the appointment is not based upon competence or merit and the job may not be offered to the best person. Although 94 (74.6 percent) respondents specified that recruitment into the workplace had been fair, 20 (15.9 percent) were of the view that people who spoke a common language were recruited and nursing mothers were discriminated against. The effects were enormous and very often the person who was offered the job could not cope with the tasks involved, resulting in incompetence and in most cases the collapse of the organisation. Such interferences conflicted with the job of the HR manager as regards the appropriateness of recruitment and selection procedures for candidates who were looking for jobs.

\section{The Concept of "Dwanetoa" (a customary practice of conflict resolution whereby a third party intercedes on behalf of an offender) In Formal Organisation}

Over the years several approaches have been adopted by traditional authorities and formal organisations in mediating and resolving conflicts. The "dwanetoa" concept is an institutional arrangement for seeking redress in the traditional set up. "Dwanetoa" in reality is an act of interceding on behalf of an offender. Traditionally, it is a recognised system, which involves a third party. Mostly the third party can be a traditional leader, a person of repute, either a kinsman of the complainant or that of the authority with whom one has a problem. The concept describes a traditional form of appeal for clemency by another, who has wronged a person, a group, kinsman or an organisation and has admitted the guilt or the offence. The offender knows he has committed an offence and goes in for an intercessor. "Dwanetoa" is seen best in litigation in court where one is to be fined or foresees trouble. In such situation the offender uses "dwanetoa" as a means to redress the problem. Depending on the gravity of the offence, the offender is forgiven freely or asked to pay a token either in kind or cash as compensation to the offended.

However, at the formal workplace, for effective and efficient interaction of persons the practice is different. To achieve organisational goals the Max Weber's bureaucratic concept is seen to be one of the best models. The model emphasizes strict compliance of laid down procedures and rules regulating behaviour of individuals in a formal organisation. As such when someone acts contrary to any of the rules, the procedure for correction is applied. To ensure fairness and 
objectivity such practice does not allow for irrational actions or decisions. In this respect, the respondents were asked to indicate if anybody had pleaded on their behalf for being punished at work. Majority of the respondents (86: 68.3 percent) answered negatively but 40 (31.7 percent) said that they had requested for top officials to plead on their behalf.

A bureaucratic structure involves impersonality that is supposed to create fairness because nonrational factors for example; personal relationships have no function in the system. The system is strict and insistent on rules and procedures. Many people are of the opinion that the "dwanetoa" concept if transferred to formal organisation would lead to their dysfunctioning. To the proponents the concept will be dysfunctional because it by-passes the formal structural arrangements and makes use of procedures not factored into the formal system. The person who is consulted to mediate may not be knowledgeable in the organisational regulations. Even if at all, appealing to factors other than what the organisation permits, bends the rules. Thus, the concept and its practice deviates from the norms of Weberian formal organisations. Hence, the hypothesis that "dwanetoa" undermines the efficient performance of HR specialist was significant in the study.

The application of "dwanetoa" in the formal organisation will be based on goodwill, kindness and borders on issues of morality or the consequences of the sanctions on the offender. Considering the actions and inactions of the offender, formal organisational rules have been broken. Issues of morality do not matter. The offender needs to be punished to serve as a deterrent and a corrective measure to promote good behaviour. The practice of the concept has introduced some dysfunctions into the operations of public sector organisations. It sets precedence by compromising organisational principles and thus, undermines discipline, fairness and objectivity. This is because once the concept is applied in one case the administrator of the rule is put in a dilemma and cannot follow con- sistently the laid down rules again. He/she has to depart from the norm.

Notwithstanding the functional difficulties, the transfer of "dwanetoa" to the formal system might create, there seems to be, an inherent benefit. It should therefore, not be completely written off. Considering the socio-cultural and even economic implications of rigid application of formal rules on individuals, "dwanetoa" could be allowed to operate along side the rules and regulations of an organisation. For example, misdemeanours should be settled informally. Again, disputes involving two employees should be allowed to rest if one of the parties involved accepts guilt and asks a third person to intercede on his/her behalf.

In such circumstances "dwanetoa" may open ways for reconsidering issues on their own merit, for example, the head or the executor of the rule will rethink and be humane enough or not be too personal with issues. "Dwanetoa" may alert people to some elements of the issues if the case is considered. The concept is likely to serve as or have a cushioning effect on the rigid bureaucratic system since the concept allows a third party to temper justice with mercy. Moreover, it creates a leeway for the HR specialist to set aside the bureaucratic hard and fast rules and deal with issues with a human face. This is particularly used in redressing deviant behaviour in an organisational setting. "Dwanetoa" may indirectly serve as a social control mechanism because if used properly it will smoothen strained social relations. People will learn to forgive and let go any intention of revenge. It may also create new relationship and interactions with people (group or organisation) and establish healthy links (only if the appeal is accepted). But if the "dwanetoa" is rejected then it may create hostilities. However, the concept of "dwanetoa" has the potential to undermine the effective running of the organisation if it is not used cautiously.

Based on the merits and demerits of each case, conditions and situations, a blend may be beneficial in enhancing achievement of organisational

66 Journal of Science and Technology, Vol. 28, No. 3, Dec., 2008 
objectives. Nonetheless, there is the need for a much more detailed study of the concept of "dwanetoa" to allow for a better blending of the two systems. "Dwanetoa" therefore could be adopted to serve as an opening for marrying traditional and rigid formal system of redressing deviant acts.

From the regression results, testing the hypothesis whether dwanetoa undermines the efficient performance of HR specialists, the null hypothesis (Ho) was accepted and the alternative hypothesis rejected. This was based on the entire variations (51 percent) of the explanatory variables regressed on the dependent variable (i.e. the $\mathrm{R}^{2}$ ) explaining the positive influence of dwanetoa in the efficient performance of $\mathrm{HR}$ specialists coupled with a high probability value which significant at 0.05 levels. The acceptance of the null hypothesis was further confirmed by the explanatory variables which were significant at the 0.05 levels.

\section{Male Bias and HRM}

Male bias in the Ghanaian social structure consists of bias concerning the sexual division of labour, which means that some particular jobs are reserved for men while others are for women. In this regard the respondents were asked if they would prefer to work with colleagues of the opposite sex. Majority of them
(111: 88.1 percent) who were mostly males answered negatively and only 15 (11.9 percent) indicated that they would prefer to work with anybody in the organization.

In most societies, men are seen as the head of the home, who have the final say and are treated as such. This practice has been carried down to the work systems in such a way that male dominance prevails in work places posing danger to the advancement of women. In the upbringing of children, the importance of the boy's education is paramount as compared to that of the girl child who is always confined to the kitchen. This has resulted in the dominance of men at work places, thus they occupy most of the leadership positions. A few of the women who make it to the top have difficulty in giving of their best because of the frustration they face in a male dominated environment.

It must be emphasized that women are not seen to be progressing much in their work due to the traditional roles that overburden them. Whilst their male counterparts have ample time to enhance themselves (through training and so on) they are rather stuck at home. It behoves the HR manager to dichotomize this dual role of the woman so as to bring out the best in them and to ensure equity between men and women at the work place.

From the above, it is clear that traditionally

Table 2: F-statistics for whether or not Dwanetoa undermines the performance of HR specialist in public organization

\begin{tabular}{cccccccccc}
\hline & R & R Square & $\begin{array}{c}\text { Adjusted R } \\
\text { Square }\end{array}$ & $\begin{array}{c}\text { Std. Error of } \\
\text { the Estimate }\end{array}$ & Change & Statistics & & \\
Model & & & & $\begin{array}{c}\text { R Square } \\
\text { Change }\end{array}$ & F Change & df1 & $\begin{array}{c}\text { df2 } \\
\text { Sig. F } \\
\text { Change }\end{array}$ \\
\hline 1 & .715 & .511 & .454 & .39844 & .511 & 8.986 & 13 & 112 & .000 \\
\hline
\end{tabular}

a) Predictors: (Constant), How long have you been working at Komfo Anokye Teaching Hospital (KATH)?, If yes to the above, what was his/her status at that time?, Have you been punished again for any other offence after the one above?, Department, Rank, Marital status, Educational qualification, Sex, Were you forgiven?, Have you repeated the offence for which you were punished?, If yes, why did you choose him/ her over others?, Age, Did you ask that person to intercede for you?

b) Dependent variable: Has anybody pleaded on your behalf for being punished at work? 
women are bestowed with certain duties in the home, especially reproductive roles as well as household chores. These, may not have caused too much problems in the past when women were basically housewives. In the contemporary world, women like men would like to develop their potential and contribute their quota towards the socio-economic development of their societies. This is not to say that, they have relinquished their reproductive roles or household chores.

\section{RECOMMENDATION}

The following recommendations were made with the view to improve the role of HR function in a socio-cultural environment, in the opinion of the author. If the recommendations are carried out successfully, the role of the HRM in the public and civil service may improve.

Management should do well to encourage and support women to take up courses to enable them upgrade themselves into higher managerial positions. There is abundant evidence that women can match men in managerial work organisations. One of the key qualities women bring to the job is emotional intelligence. Also, women are able to do things men can do as well as things men cannot do, thus making women unique. Thus, women should build on these strengths rather than see their femininity as a hindrance. It is recommended that everybody in a position to help women in the public sector should work hard to help them in their career enhancement endeavours so that collectively both men and women would effectively and efficiently contribute to organisational development.

There is the need to have built-in mechanisms in terms of awareness creation so that the workers become aware that the work organisation is different and independent of the traditional values and socio-cultural factors of the society of which they belong. Understanding this concept will greatly reduce and in future eradicate the conflict between the demands of the work organisation and family expectations that confront HR officers in the performance of their jobs.

Cultures differ among various societies with time. Peoples' cultural values are said to be very dear to their hearts. These same people must work to be able to survive and take care of their family, whether nuclear or extended. If a person works on his/her own he can do without any organisational rule. But once a person decides to work in a formal (bureaucratic) organisation he/ she must be prepared to submit to the rules and regulations in the organisations. However, strict adherence to rules and regulations make it difficult for people to practice their culture, which forms part of their values. It would therefore be appropriate if HRM practices and cultural practices were worked out in a way that would ensure harmony in the public institutions.

\section{CONCLUSION}

The traditional values and socio-cultural factors have put strains on the effective and efficient performance of the roles of HR managers. There are situations where the HR manager has to bend the rules in order to satisfy the demands of kinsmen at the expense of established organisational norms.

A functional role of HRM in the public sector organisations includes opportunities for the HR specialist to act as an agent of change. However, cultural and social aspects are decisive in the role of HR managers, for example, the effect of "dwanetoa", funerals and attitudes on HRM. Therefore, operating an HR department in the public sector organisations may be rather different from running a department somewhere else. Hence, the application of inappropriate strategies is often a source of conflict, and this may be quite acute when seeking a choice for a change strategy.

It is therefore imperative to say that in spite of rapid changes the Ghanaian society has undergone, it still retains most of the norms of its traditional society for most of its people living in the traditional social organisation. The focus of life is gradually shifting to the urban centres, but

68 Journal of Science and Technology, Vol. 28, No. 3, Dec., 2008 
traditional values and socio-cultural factors are certainly not left behind. The traditional values and socio-cultural factors, which the society maintains, remain strong among workers in spite of the conflicting values prescribed by the public sector organisations.

\section{REFERENCES}

Akinnusi, D. (1993). Personnel Management in Africa: A Comparative Analysis of Ghana, Kenya and Nigeria, in C. Brewster and S. Tyson. (1993). International Comparisons in Human Resource Management, Pitman Publishing, London: 162-164.

Armstrong, M. (1992). .A Handbook of Personnel Management Practice, Kogan Page Limited, London: 67.

Armstrong, M. (2001). A Handbook of Human Resource Management Practice, Kogan Page Limited, London: 3-4.

Assimeng, M. (1999). Social Structure of Ghana: A Study in Persistence and Change, Ghana Publishing Corporation, Tema: 2845 .

Lyons, T.P. (1971). Personnel Function in a Changing Environment, Pitman Publishing Limited, London: 3.
Moser, C.O.N. (1993). Gender Planning and Development: Theory, Practice and Training, Routledge, New York: 53-102.

Nukunya, G., (1992). Tradition_and Change in Ghana: An Introduction to Sociology, Universities Press, Accra: 235.

Nukunya, G. (2003). Tradition and Change in Ghana: An Introduction to Sociology, Universities Press, Accra: 230-245.

Ollennu, N. A. (1966). A Study of Contemporary Ghana, George Allen and Urwin Limited, London: 71-74.

Peil, M. (1972). The Ghanaian Factory Worker, Cambridge University Press, Cambridge: 98.

Price, R. (1975). Society and Bureaucracy in Contemporary Ghana, University of California Press, California: 59.

Sarpong, P. (1974). Ghana in Retrospect: Some Aspects of Ghanaian Culture, Ghana Publishing Corporation, Accra: 26-32.

Tyson, S. and Fell, A. (1985). Evaluating Personnel Function, Century Hutchinson Limited, London: 10. 